\title{
Proceeding
}

7th INSHS International Christmas Sport Scientific Conference, 9-12 December 2012. International Network of Sport and Health Science. Szombathely, Hungary

\section{An experimental study on Aerobic Gymnastic: performance analysis as an effective evaluation for technique and teaching of motor gestures}

\author{
GAETANO RAIOLA , YLENIA GIUGNO, ISABELLA SCASSILLO, PIO ALFREDO DI TORE \\ Department of Human, Philosophical and Education Sciences (DISUFF) University of Salerno, Italy
}

\begin{abstract}
Raiola G, Giugno Y, Scassillo I, Di Tore PF. An experimental study on Aerobic Gymnastic: performance analysis as an effective evaluation for technique and teaching of motor gestures. J. Hum. Sport Exerc. Vol.8, No. Proc2, pp. S297-S306, 2013. Aerobic Gymnastic is the ability to perform complex movements produced by the traditional aerobic exercises, in a continuous manner, with high intensity, perfectly integrated with soundtracks. This sport is performed in an aerobic/anaerobic lactacid condition and expects the execution of complex movements produced by the traditional aerobic exercises integrated with difficulty elements performed with a high technical level. An inaccuracy about this sport is related to the name itself "aerobic" because Aerobic Gymnastic does not use just the aerobic work during the competition, due to the fact that the exercises last among 1'30" and 1'45" at high rhythm. Agonistic Aerobics exploit the basic movements of amateur Aerobics and its coordination schemes, even though the agonistic Aerobics is so much intense than the amateur Aerobics to need a completely different mix of energetic mechanisms. Due to the complexity and the speed with which you perform the technical elements of Aerobic Gymnastic, the introduction of video analysis is essential for a qualitative and quantitative evaluation of athletes' performance during the training. The performance analysis can allow the accurate analysis and explanation of the evolution and dynamics of a historical phenomenon and motor sports. The notational analysis is used by technicians to have an objective analysis of performance. Tactics, technique and individual movements can be analyzed to help coaches and athletes to re-evaluate their performance and gain advantage during the competition. The purpose of the following experimental work will be a starting point for analyzing the performance of the athletes in an objective way, not only during competitions, but especially during the phases of training. It is, therefore, advisable to introduce the video analysis and notational analysis for more quantitative and qualitative examination of technical movements. The goal is to lead to an improvement of the technique of the athlete and the teaching of the coach. Key words: PERFORMANCE ANALYSIS, VIDEO ANALISI, VALUTAZIONE QUALITATIVA E QUANTITATIVA, TECNICA, DIDATTICA.
\end{abstract}

Corresponding author. Gaetano Raiola, Via Berenice 11, Napoli, Italy.

Email: raiolagaetano@libero.it

7th INSHS International Christmas Sport Scientific Conference, 9-12 December 2012. International Network of Sport and Health Science. Szombathely, Hungary.

JOURNAL OF HUMAN SPORT \& EXERCISE ISSN 1988-5202

(c) Faculty of Education. University of Alicante

doi:10.4100/jhse.2012.8.Proc2.32

VOLUME 8 | Proc2 | 2013 | S297 


\section{INTRODUCTION}

Aerobic Gymnastic is the ability to perform complex movements produced by the traditional aerobic exercises, in a continuous manner, with high intensity, perfectly integrated with soundtracks. This sport is performed in an aerobic/anaerobic lactacid condition and expects the execution of complex movements produced by the traditional aerobic exercises integrated with difficulty elements performed with a high technical level.

An inaccuracy about this sport is related to the name itself "aerobic" because Aerobic Gymnastic does not use just the aerobic work during the competition, due to the fact that the exercises last among 1'30" and 1'45" at high rhythm (Righetti, 2007). Agonistic Aerobics exploit the basic movements of amateur Aerobics and its coordination schemes, even though the agonistic Aerobics is so much intense than the amateur Aerobics to need a completely different mix of energetic mechanisms.

At the end of ' 80 s the first aerobic competition have been organized by some associations, first of all the FISAF (Federation Internationale de Sport Aerobic et Fitness), which drew up the rule book and the evaluation codes that stressed the choreographic feature a lot. In a setting with such less detailed - and hence less binding - rules, time after time, many athletes started to introduce new difficulty elements coming from different sports such as dance, artistic and rhythmic gymnastics, martial Arts so that step by step the international associations of agonistic aerobics have aligned their evaluation to those new and spontaneous tendencies.

On 05/13/1994, day of the 69th FIG (Federazione Internazionale Ginnastica) Congress, the acknowledgement and the first insertion of the Aerobic Gymnastic among the sports of the International Association, and nowadays the $\mathrm{FGl}$ is the only league that officially promote this sport worldwide thanks to the International Olympic Committee (IOC) and the General Association of International Sports Federations (GAISF).

On September 1994, in Paris, has been held a meeting IOC-GAISF. That meeting could be considered historic because the Aerobics clubs and international associations, for the first time, were invited to encounter and edit the rules of this sport. Not all the invited took part at the meeting.

On October 1994, in a GAISF general meeting the FIG was recognized as the only official Aerobics league and the importance of unifying all the associations was confirmed.

On June 1995, a second reunion was held to join all the associations together, and on December of that year, the first World Championship was organized with the participation of 34 FIG National teams.

On October 1996, during the European Gymnastic Union (EGU) meeting the characteristics of the first European Championship were codified, and in that year, in Nederland the second World Championship took place.

Nowadays, 10 World Championship have been organized, 3 Juniors International Championship, 5 European Championship, 3 World Cup Finals; besides, this sport took part to the last two World Games and has long been the FIG is trying to make the Aerobics enter into the Olympic sport program. On January 2001, the Aerobic Gymnastic has become an autonomous section of the Italian Gymnastic Association and that fact requires us to constantly and more deeply study the features of this sport. 
Due to the complexity and the speed with which you perform the technical elements of Aerobic Gymnastic, the introduction of video analysis is essential for a qualitative and quantitative evaluation of athletes' performance during the training. The performance analysis can allow the accurate analysis and explanation of the evolution and dynamics of a historical phenomenon and motor sports. "The notational analysis is a technique to analyze different aspects of performance through a process which involves a permanent registration of the events. The performance analysis tools are: annotations in real time and also deferred through the use of video-software by experts, coaches and analysts specifically trained" (Raiola \& Di Tore, 2012a, 2012b). Tactics, technique and individual movements can be analyzed to help coaches and athletes to re-evaluate their performance and gain advantage during the competition.

The purpose of the following experimental work will be a starting point for analyzing the performance of the athletes in an objective way, not only during competitions, but especially during the phases of training. It is, therefore, advisable to introduce the video analysis and notational analysis for more quantitative and qualitative examination of technical movements. The goal is to lead to an improvement of the technique of the athlete and the teaching of the coach.

\section{MATERIAL AND METHODS}

Table 1. Valuation techniques commonly used by coaches during training sessions of Aerobics

\begin{tabular}{lcc}
\hline \multicolumn{1}{c}{ Name of the technical } & $\begin{array}{c}\text { Score of the element determined } \\
\text { by F.G.I. }\end{array}$ & Final score on a scale out of 10 \\
Push up & 0.10 & \\
Wenson Push up & 0.30 \\
Straddle Support & 0.20 \\
L-Support & 0.20 \\
Tuck Jump & 0.20 \\
Cossack Jump & 0.30 \\
1/1 Air Turn & 0.30 \\
Vertical Split & 0.20 \\
1/1 Turn to Vertical Split & 0.40 \\
\hline
\end{tabular}


Table 2. Quantitative assessment of the technical evaluation by referring to the tables of the judges, taking into account the descriptors and the minimum requirements set by the Code of Scores of the FGI

\begin{tabular}{|c|c|c|c|}
\hline Name of the technical & $\begin{array}{l}\text { Score of the element } \\
\text { determined by F.G.I. }\end{array}$ & Score deduction & Final score \\
\hline Push up & 0.10 & & \\
\hline Wenson Push up & 0.30 & & \\
\hline Straddle Support & 0.20 & & \\
\hline L-Support & 0.20 & & \\
\hline Tuck Jump & 0.20 & & \\
\hline Cossack Jump & 0.30 & & \\
\hline 1/1 Air Turn & 0.30 & & \\
\hline Vertical Split & 0.20 & & \\
\hline 1/1 Turn to Vertical Split & 0.40 & & \\
\hline
\end{tabular}

Table 3. Quantitative assessment with video support and analysis of the gesture with the help of software Kinovea

\begin{tabular}{|c|c|c|c|}
\hline Name of the technical & $\begin{array}{l}\text { Score of the element } \\
\text { determined by F.G.I. }\end{array}$ & $\begin{array}{l}\text { Score deduction with the support } \\
\text { of video analysis }\end{array}$ & $\begin{array}{l}\text { Final } \\
\text { score }\end{array}$ \\
\hline Push up & 0.10 & & \\
\hline Wenson Push up & 0.30 & & \\
\hline Straddle Support & 0.20 & & \\
\hline L-Support & 0.20 & & \\
\hline Tuck Jump & 0.20 & & \\
\hline Cossack Jump & 0.30 & & \\
\hline 1/1 Air Turn & 0.30 & & \\
\hline Vertical Split & 0.20 & & \\
\hline 1/1 Turn to Vertical Split & 0.40 & & \\
\hline
\end{tabular}


The quantitative evaluation will give an athlete a first score, without the support of video analysis, taking into account the minimum requirements of technical movements in the Code of Points of Aerobics Gymnastics. The technician will examine the athlete on the base of the initial score by removing tenths for any executive errors if they do not met the requirements. In a second step we will divide the athletes into two groups: the group number 1 will simply continue his training while the technician will be filling evaluation forms without video support, once a week for six months; the group number 2 instead will be evaluated through the video analysis, once a week for 6 months. Both the groups will be formed by 3 athletes, aged between 10 and 12 years, with different technical abilities, so as to assess the effectiveness of the method is to high or medium levels that at basic levels. The technician will examine in a second time the gesture examined by analyzing errors made by each athlete. Through the use of four cameras, placed in the four corners of the training hall, one will have a full assessment of the movement in examining different points that will help the technician to identify errors hardly visible to the naked eye. The athletes will perform a basic element of the discipline: the Push Up. The body from a leaning back position, performs a bending on the arms with phase of descent and ascent and then return to the very starting position. The use of video analysis will allow us to slow down the video, analyze and synchronize the photos you want to examine for 4 cameras, draw a line passing through the body landmarks in order to have a more accurate alignment of the head, shoulder, hip and heel and assess the correct posture before performing the gesture. The same analysis will be carried out even in the descent phase in order to examine whether there is a proper alignment of the body.

Only at the end of the experimental phase the evaluations of the two groups will be compared, the differences and possible improvements of the group who has been training with video support will be noted to verify whether or not the use of performance analysis in Aerobic Gymnastics may be effective. In such a complex sport the video analysis is extremely important as it will allow us analyzing in more detail the technique and the implementation of certain technical gestures difficult to examine to the naked eye, due to the execution speed of the elements of difficulty. The software used is the open source Kinovea that will slow down the video to be scanned, select the key images as main points to analyze, track the movement through the markers placed on a part of the body in order to draw its motion, time the whole movement, measure angles and distances after establishing a priori a basic segment. All this will slow down the movement, analyze the technical difficulties and improve its implementation. 


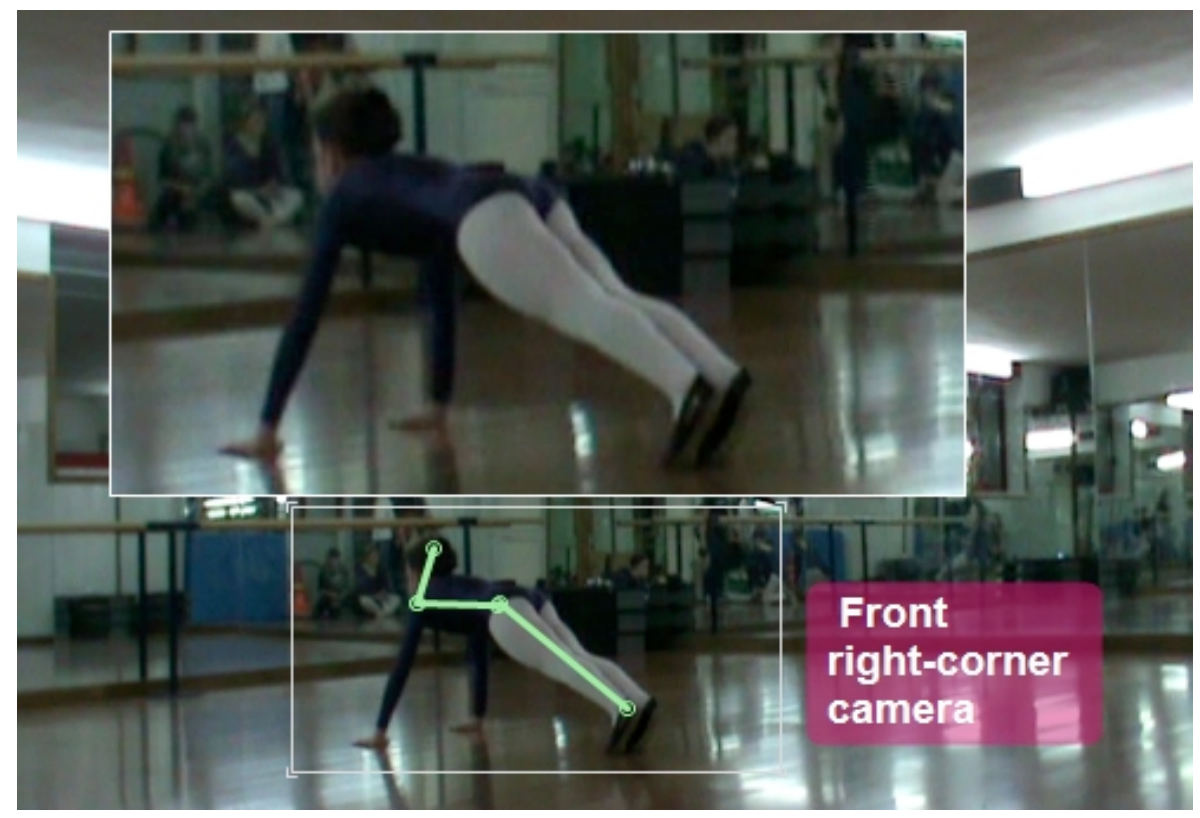

Figure 1. Video analysis evaluation of Push Up: start position.

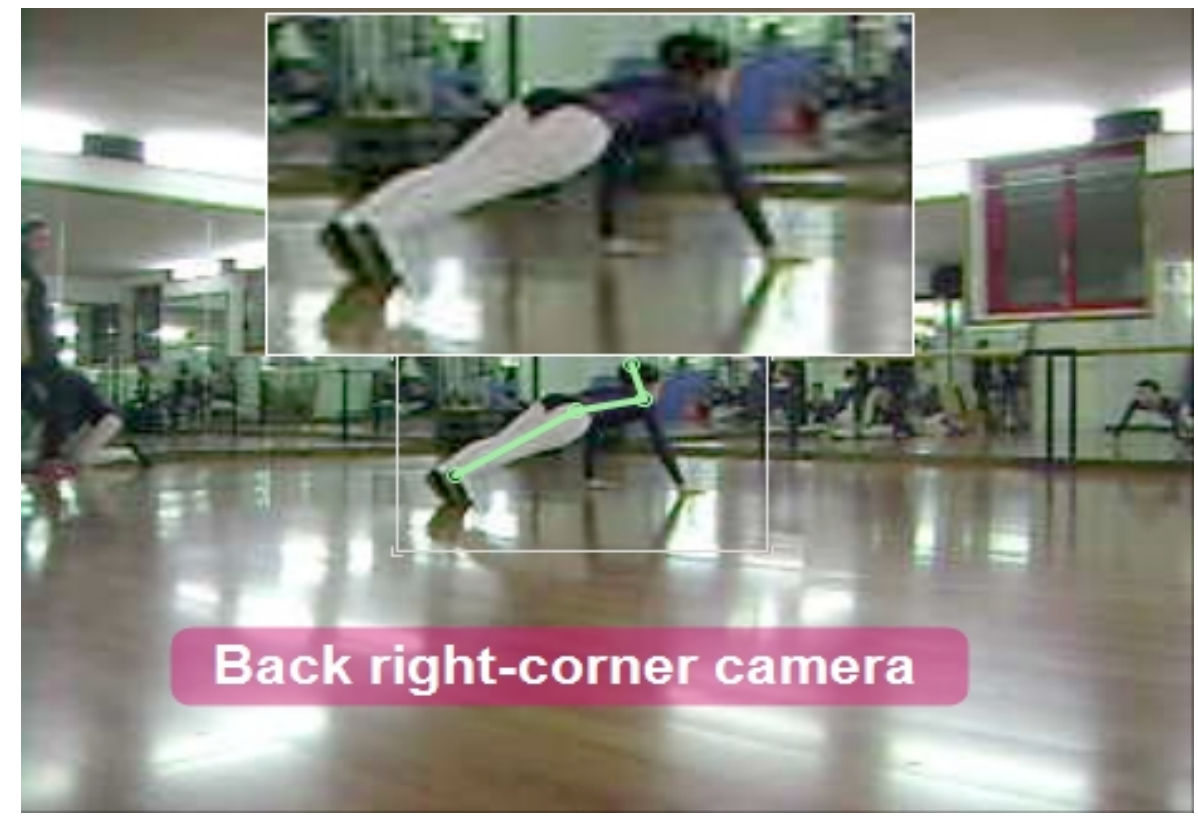

Figure 2. Video analysis evaluation of Push Up: start position. 


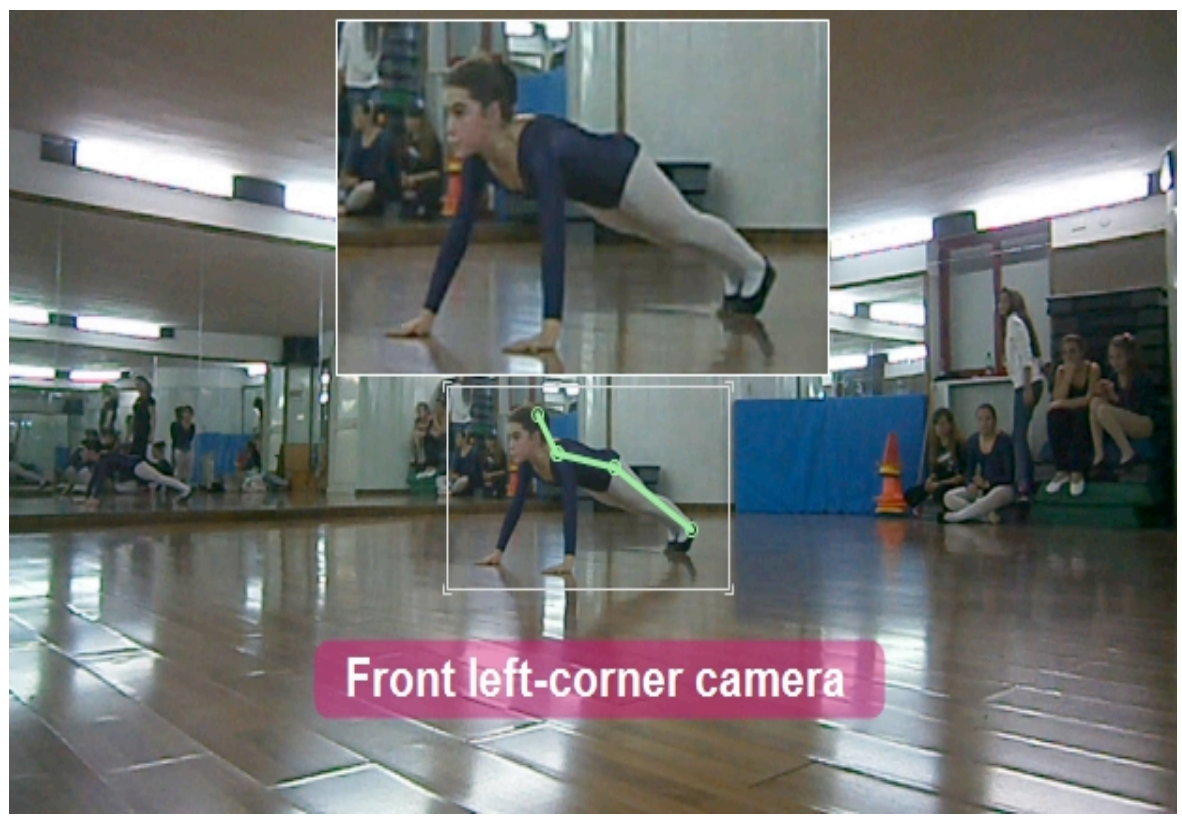

Figure 3. Video analysis evaluation of Push Up: start position.

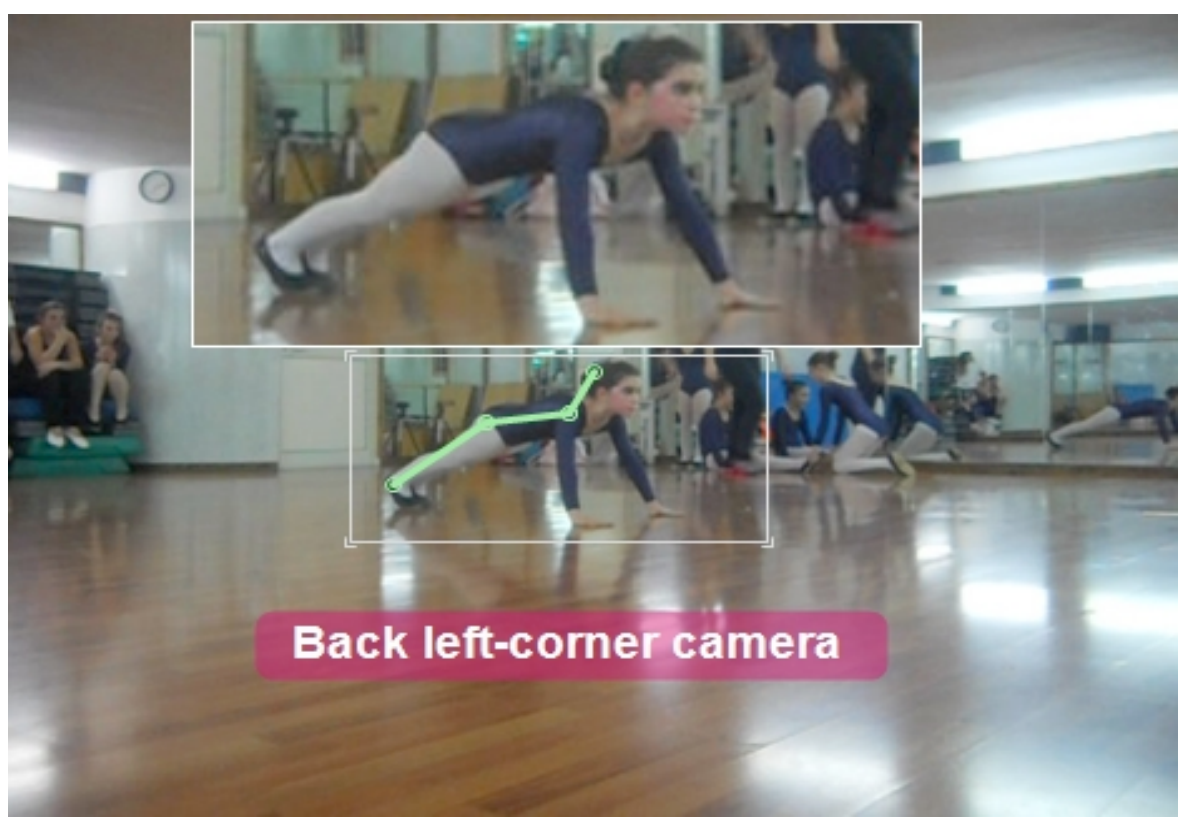

Figure 4. Video analysis evaluation of Push Up: start position. 


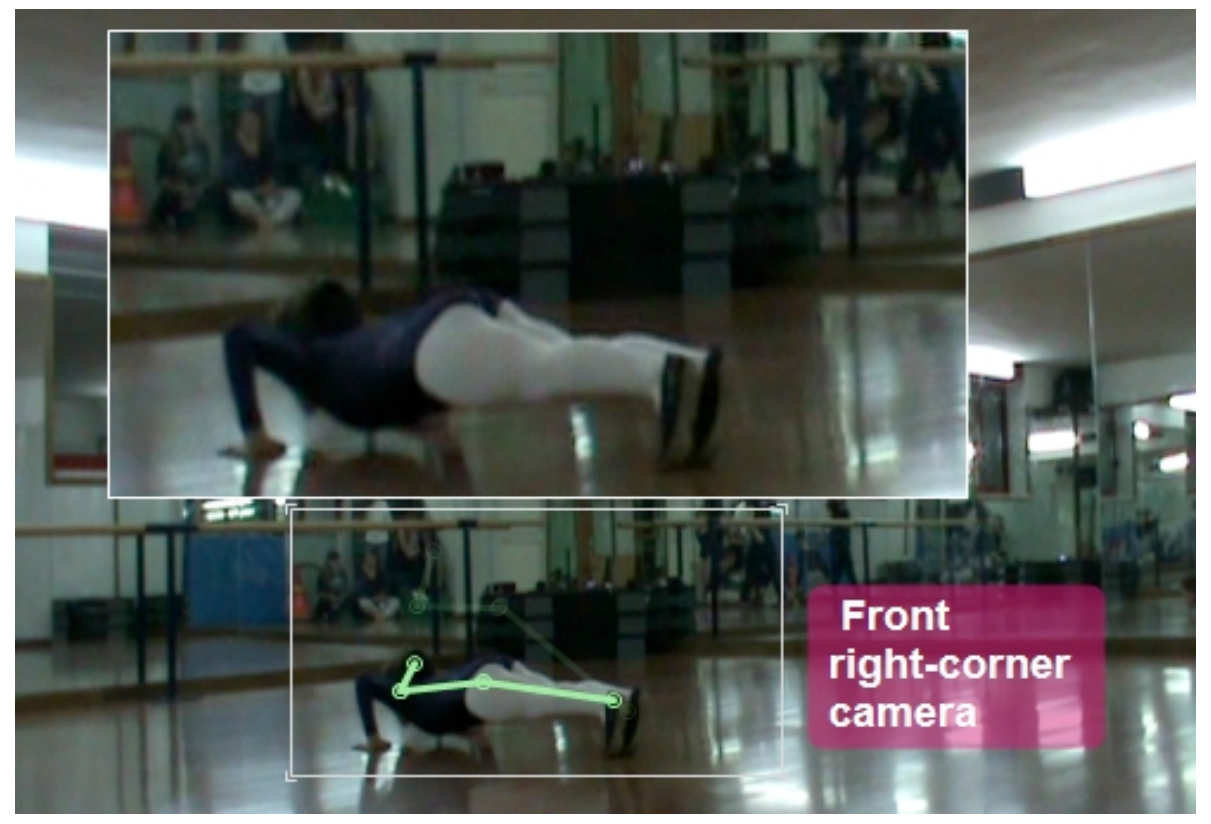

Figure 5. Video analysis evaluation of Push Up: descent phase.

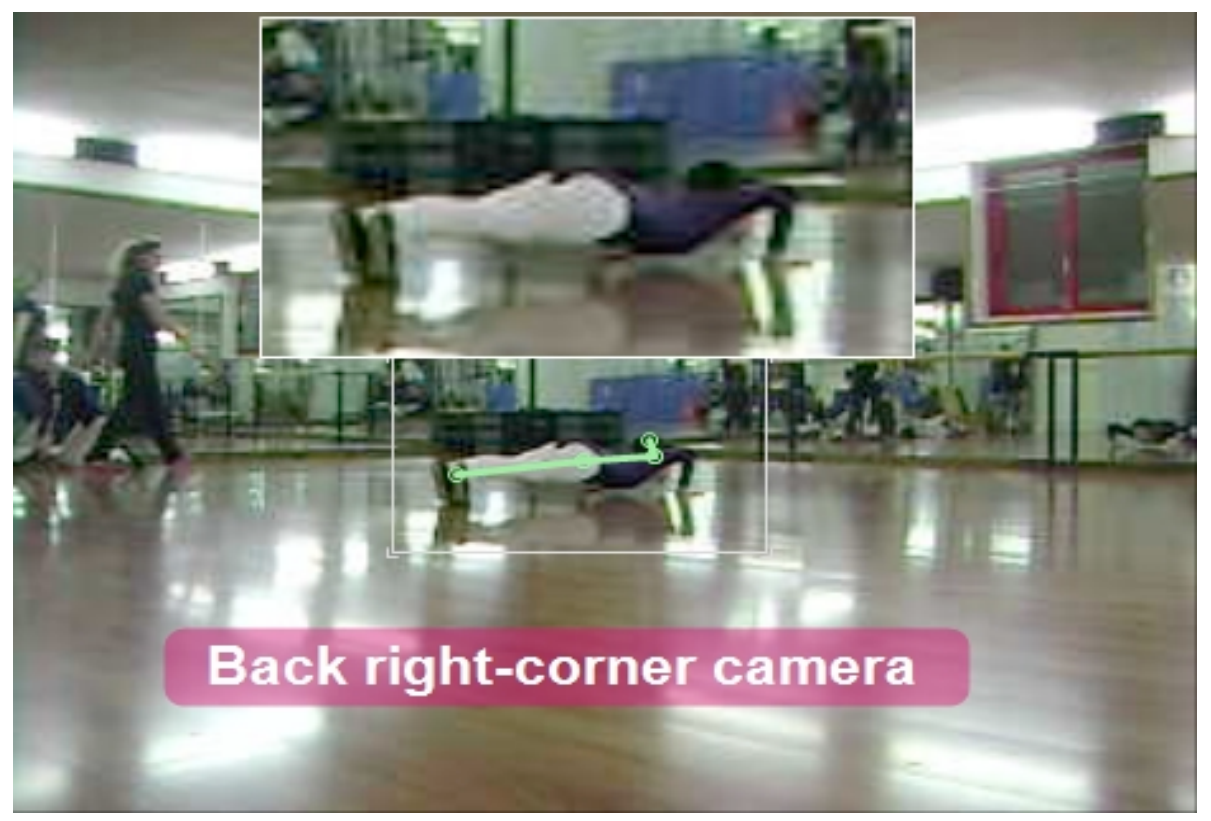

Figure 6. Video analysis evaluation of Push Up: descent phase. 


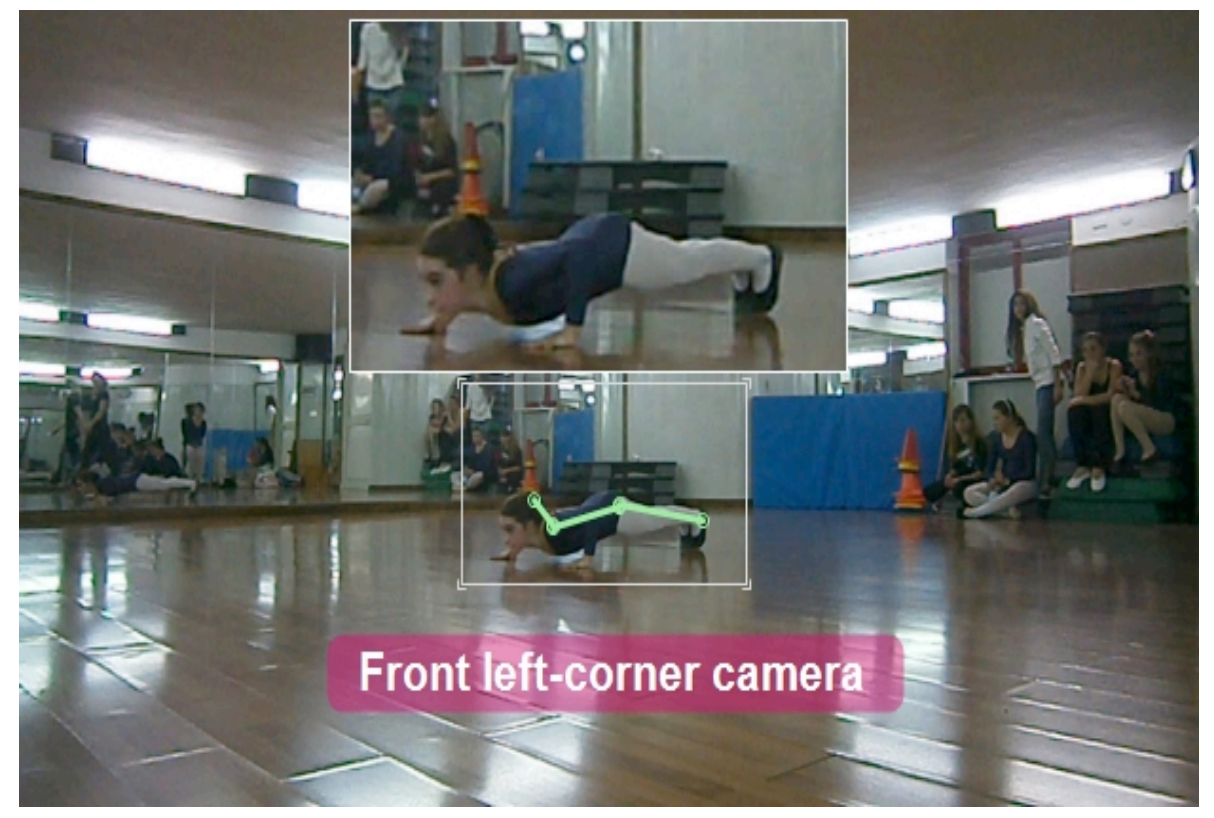

Figure 7. Video analysis evaluation of Push Up: descent phase.

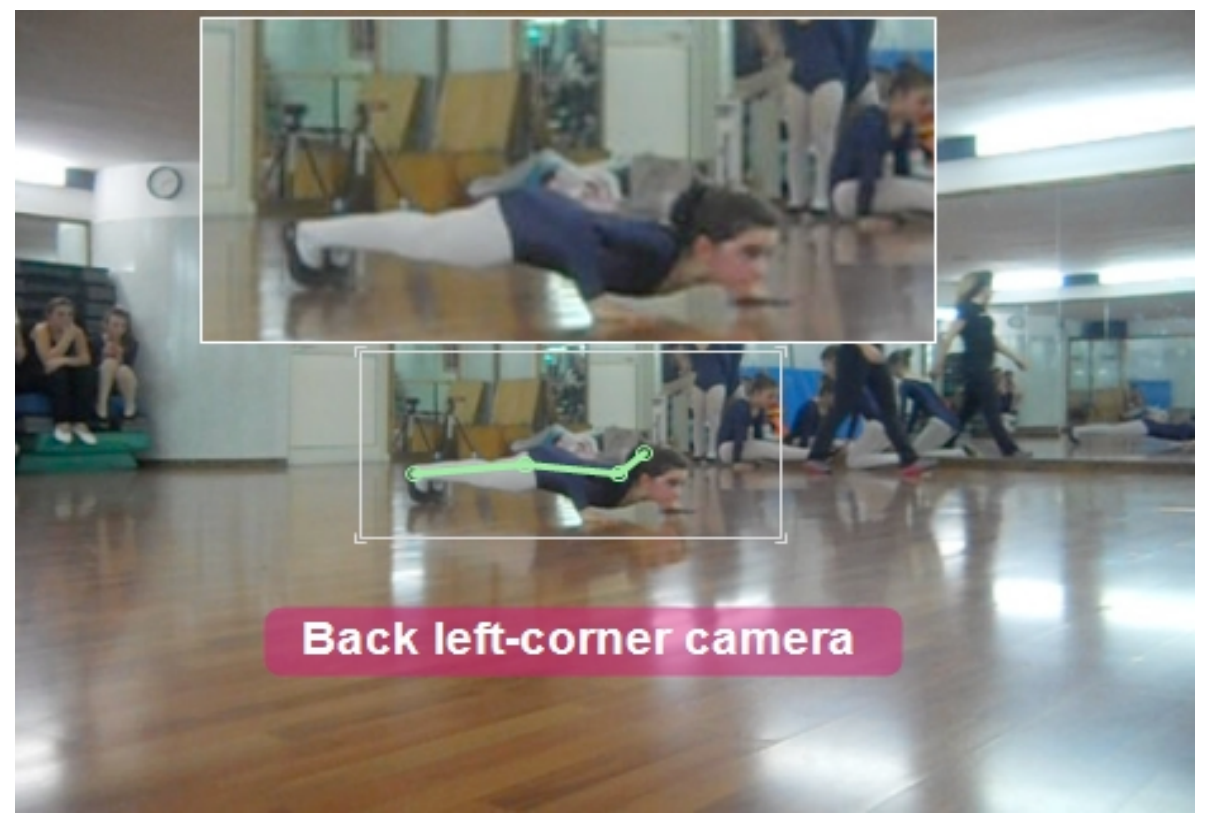

Figure 8. Video analysis evaluation of Push Up: descent phase. 


\section{RESULTS}

At the end of the work, still in the experimental stage, will be compared to the evaluation of the two groups. The end of the research, it is desirable to find improvements in the experimental group assessed with the video analysis in comparison with the control group which will be evaluated instead just by filling in cards and with the direct observation of the technician. The expected results of the exercise will help the technician to identify, analyze and correct errors made by the athletes more quickly than the mere visual assessment will take the group number 1 . It is desirable that the introduction of video analysis will lead to an improvement of the group number 2 with respect to group number 1 as regards the rapidity of correction of the gesture. While for the technician will be easier to adopt new teaching strategies to be presented to athletes for better technical correction, teaching and executive action.

\section{DISCUSSION}

This project therefore provides an improved evaluation of athletic performance that will be analyzed in a more objective and analytical manner than commonly done, trying to give an explanation for any technical error with tools ever used in Aerobic Gymnastics. At the end of the work new evaluation form scan be introduced similar to those used by the judges during the competition, for an objective analysis even during training. This new method of analysis can then be tested also on athletes, in order to self-assess by reviewing the movie, understand what are the mistakes, how to correct them with the help of the technician more quickly and be more aware of their inaccuracies.

It is desirable, at the end of the work, to reach a conclusive effective assessment of the new method after a possible experimental use ofit.

\section{REFERENCES}

1. Codice dei Punteggi, www.federginnastica.it (2008-2012).

2. HUGHES M, LIPOMA M, SIBILIO M. La performance analysis. Elementi di base e aspetti applicativi in campo educativo e integrativo. Milano: Franco Angeli, 2009.

3. HUGHES MD, FRANKS IM. National analysis of Sport 2nd Edition- better system for improving coaching and performance, London: E. \& F.N. Spon. UK, 2004.

4. HUGHES M, BARTLETT R. Special edition on performance analysis. Journal of Sport Sciences, UK. 2002; 20: 735-737.

5. RIGHETTI L. "Modelli di prestazione della Ginnastica Aerobica", Facoltà di Medicina e Chirurgia, Università degli Studi di Roma; Giudice Internazionale di Ginnastica Aerobica, Italy. 2007/2008.

6. RAIOLA G. "La complessità dello studio in ambito sportivo educativo", lecce: pensa, Italy.

7. RAIOLA G, DI TORE P. Statistical study on bodily communication skills in volleyball to improve teaching methods. Journal of Human Sport and Exercise. 2012; 7(2): 468-488.

8. RAIOLA G, DI TORE P. Bodily communication skills and its incidence on female volleyball championship to enhance didactics. Journal of Human Sport and Exercise. 2012; 7(2): 365-375.

9. Software Kinovea@, www.kinovea.org. 